\title{
Pengaruh Suhu Aktivasi Terhadap Morfologi dan Jumlah Pori Karbon Aktif Tempurung Kemiri sebagai Elektroda
}

\author{
Zudit Efendi*, Astuti \\ Jurusan Fisika FMIPA Universitas Andalas, Padang \\ Kampus Unand Limau Manis, Pauh Padang 25163 \\ *Zudit1412.ze@gmail.com
}

\begin{abstract}
ABSTRAK
Telah dibuat elektroda dari karbon aktif tempurung kemiri (Aleurites molucanna) dengan $\mathrm{H}_{3} \mathrm{PO}_{4} 2,5 \%$ sebagai aktivator dengan suhu aktivasi $600{ }^{\circ} \mathrm{C}, 700{ }^{\circ} \mathrm{C}$, dan $800{ }^{\circ} \mathrm{C}$. Jumlah mesopori karbon aktif yang dihasilkan berturut-turut adalah 208, 2381, dan 942 pori. Luas permukaan pori karbon aktif adalah 444426,57 , 12910253,53, dan 3466400,00 $\mathrm{nm}^{2}$. Nilai konduktivitas listrik elektroda yang diperoleh adalah 0,02, 0,03, dan 0,04 $\mu \mathrm{S}$. Untuk nilai kapasitansi adalah 9,44, 15,13, dan 8,76 $\mathrm{FF}$. Sehingga elektroda terbaik dihasilkan pada suhu aktivasi $700{ }^{\circ} \mathrm{C}$.

Kata kunci: Cappacitive deionization, elektroda, $\mathrm{H}_{3} \mathrm{PO}_{4}$, Karbon aktif, mesopori, tempurung kemiri
\end{abstract}

\begin{abstract}
An electrode has been made from candlenut shell (Aleurites moluccana) by using $\mathrm{H}_{3} \mathrm{PO}_{4} 2.5 \%$ as activating agent with various activation temperature of $600{ }^{\circ} \mathrm{C}, 700{ }^{\circ} \mathrm{C}$, and $800{ }^{\circ} \mathrm{C}$. The results show that activated carbon have 208, 2381 and 942 mesopores respectively. The surface area of activated carbons are 444426.57, 12910253.53, and $3466400.00 \mathrm{~nm}^{2}$. The electrode have electrical conductivity of 0.02, 0.03, and 0.04 $\mu \mathrm{S}$. The electrode have capacitance of 9.44, 15.13, dan 8.76 $\mu$ F. So the best of electrode resulted on activation temperature of $700^{\circ} \mathrm{C}$.

Keywords : Capacitive deionization, electrode, $\mathrm{H}_{3} \mathrm{PO}_{4}$, activated carbon, mesoporous, candlenut shell
\end{abstract}

\section{PENDAHULUAN}

Air sangat penting bagi kelangsungan hidup manusia. Pentingnya air tidak terlepas dari kebutuhan manusia yang beragam, salah satunya untuk keperluan rumah tangga. Air yang digunakan adalah air tawar yang tidak berasa asam, manis, pahit atau asin. Rasa asin disebabkan terdapatnya garam-garam tertentu yang larut dalam air, sedangkan rasa asam dikarenakan kandungan asam organik maupun anorganik dalam air. Mengingat pentingnya air dalam kehidupan manusia maka penyediaan air tawar perlu diupayakan secara optimal, sebab diperkirakan pada tahun 2025 dua per tiga dari populasi umat manusia akan mengalami kelangkaan air bersih (Nienhuis, 2006).

Masalah tersebut dapat diatasi dengan memanfaatkan air laut. Air laut merupakan sumber air yang paling berpotensi untuk mengatasi krisis air tawar karena jumlahnya yang sangat besar dan sanggup menutupi $71 \%$ permukaan Bumi. Namun air laut tidak dapat digunakan secara langsung karena memiliki kadar garam yang tinggi yaitu sekitar 3\% (Misbah dan Nova., 2010). Agar dapat digunakan maka air laut perlu diubah menjadi air tawar dengan menerapkan proses yang dapat mengubah air asin menjadi air tawar. Proses ini dikenal dengan desalinasi.

Saat ini metode desalinasi yang sedang banyak dikembangkan adalah Capacitive Deionisation (CDI). CDI banyak dikembangkan karena biaya yang murah dan hemat energi karena dioperasikan pada tegangan DC rendah dibandingkan dengan metode yang lain seperti Electrodialysis (ED), Reverse Osmosis (RO), dan Multi-Stage Flash Evaporation (MSF) (Endarko dan Fatimah., 2013). Metode ini dilakukan dengan mengalirkan air garam melewati celah di antara elektroda yang diberi beda potensial sehingga terjadi penyerapan ion secara elektrostatis pada permukaan elektroda. Proses desalinasi dengan CDI akan efektif dan efisien jika bahan elektroda yang digunakan memiliki permukaan pori yang luas (Adhytiawan dan Susanti., 2013). Permukaan pori yang luas akan meningkatkan daya adsorbsi elektroda. Selain permukaan pori yang luas jenis pori juga berperan penting dalam proses adsrobsi. Berdasarkan penelitian yang dilakukan oleh Taspika (2014) jenis pori yang tergolong mesopori

Bahan elektroda yang banyak digunakan ialah karbon aktif. Pengembangan karbon aktif sebagai bahan elektroda pada sistem CDI dikarenakan daya adsorbsinya yang baik (Taberna 
dkk., 2004; Ramdja dkk., 2008). Selain memiliki daya adsorbsi yang baik, karbon aktif juga memiliki luas permukaan spesifik yang luas yaitu berkisar antara (400-2200) $\mathrm{m}^{2} / \mathrm{g}$ (Ariyanto dkk., 2012). Daya adsorbsi karbon aktif juga dipengaruhi oleh kandungan karbon yang terdapat dalam bahan. Oleh karena itu, karbon aktif dapat dibuat dari bahan yang banyak mengandung karbon, seperti kayu, batu bara,tempurung kelapa, dan tempurung kemiri.

Sebelumnya telah banyak dilakukan penelitian mengenai karbon aktif. Diantaranya yang dilakukan oleh Lempang dkk. (2009) yang menganalisa struktur dan komponen karbon aktif dari tempurung kemiri, Darmawan dkk. (2009) yang meneliti sifat karbon aktif dari tempurung kemiri dan Pambayun dkk. (2013) yang membuat karbon aktif menggunakan tempurung kelapa.

Pada penelitian ini akan di analisa pengaruh suhu aktivasi terhadap jumlah pori karbon aktif tempurung kemiri. Penggunaan tempurung kemiri sebagai material elektroda dikarenakan kadar karbon yang tinggi (51,08 \%), lebih tinggi jika dibandingkan dengan kayu (46,16\%), dan biji ceri (47,52\%) (Gonzalez dkk., 2003). Kandungan karbon yang tinggi pada tempurung kemiri berasal dari senyawa kimia yang terdapat pada tempurung kemiri misalnya holoselulosa dan lignin.

\section{METODE}

\subsection{Pembuatan Karbon Aktif Tempurung Kemiri}

Pembuatan karbon aktif yang berbahan dasar tempurung kemiri dimulai dengan membersihkan tempurung kemiri kemudian dikarbonasi pada suhu $750{ }^{\circ} \mathrm{C}$ selama 90 menit. Setelah didapatkan arang hasil karbonasi lalu diaktivasi secara kimia menggunakan $\mathrm{H}_{3} \mathrm{PO}_{4} 2,5$ $\%$ selama 20 jam dan aktivasi secara fisika pada suhu $600{ }^{\circ} \mathrm{C}, 700{ }^{\circ} \mathrm{C}$, dan $800{ }^{\circ} \mathrm{C}$ selama 90 menit. Selanjutnya arang aktif yang dihasilkan dinetralkan pH-nya menggunakan aquades kemudian dikeringkan pada suhu $170{ }^{\circ} \mathrm{C}$ selama 30 menit kemudian arang aktif siap digunakan.

\subsection{Pembuatan Elektroda}

PVA sebanyak $1 \mathrm{~g}$ dilarutkan dalam $10 \mathrm{~mL}$ aquades dengan cara diaduk menggunakan hot plate magnetic stirrer dan magnetic bar pada suhu $40{ }^{\circ} \mathrm{C}$ selama 15 menit. Kemudian karbon aktif sebanyak $1 \mathrm{~g}$ ditambahkan kedalam larutan PVA. Selanjutnya campuran diaduk menggunakan hot plate magnetic stirrer dan magnetic bar pada suhu $40{ }^{\circ} \mathrm{C}$ selama 2 jam. Lalu permukaan stainless steel dilapisi dengan campauran karbon aktif yang telah didapatkan seperti Gambar 1 . Kemudian dipanaskan pada suhu $50{ }^{\circ} \mathrm{C}$ selama $1 \mathrm{jam}$. Elektroda dibuat sebanyak 3 sampel.

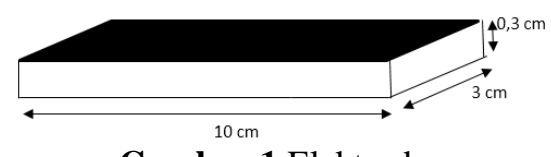

Gambar 1 Elektroda

\subsection{Pengukuran Nilai Kapasitansi dan Konduktivitas Listrik}

Nilai kapasitansi dan konduktivitas listrik diukur menggunakan LCR meter. Pengukuran dilakukan dengan cara menghubungkan kutup positif dan negatif pada masing-masing elektroda seperti Gambar 2. Konduktivitas listrik diperoleh dengan cara mengukur resistansi elektroda terlebih dahulu, kemudian dihitung nilai konduktivitas listriknya. Sedangkan kapasitansi diperoleh langsung dari pengukuran. Pengukuran dilakukan sebanyak 20 kali lalu diambil rataratanya dan hasilnya diplot dalam bentuk grafik. 


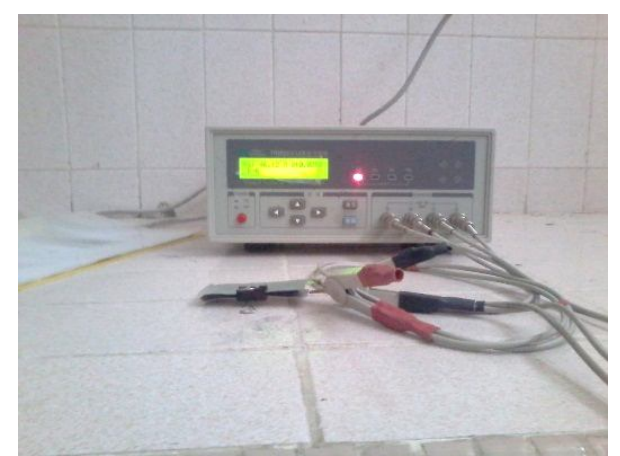

Gambar 2 Pengukuran kapasitansi dan konduktivitas listrik

\section{HASIL DAN DISKUSI}

\subsection{Morfologi Permukaan Karbon Aktif}

Morfologi permukaan karbon aktif dengan suhu aktivasi $600{ }^{\circ} \mathrm{C}, 700{ }^{\circ} \mathrm{C}$, dan $800{ }^{\circ} \mathrm{C}$ dikarakterisasi menggunakan SEM dan hasilnya ditampilkan pada Gambar 3. Pada Gambar 3 terlihat munculnya pori pada semua suhu aktivasi. Pori yang muncul berbeda untuk setiap suhu aktivasi, baik bentuk maupun ukuranya. Ukuran pori karbon aktif dengan suhu aktivasi $700{ }^{\circ} \mathrm{C}$ lebih kecil dari aktivasi $600{ }^{\circ} \mathrm{C}$, sedangkan pada suhu aktivasi $800^{\circ} \mathrm{C}$ terlihat ukuran pori yang dihasilkan lebih besar dari yang lainnya. Sehingga dapat dikatakan bahwa ukuran pori semakin besar jika suhu aktivasi diatas $700{ }^{\circ} \mathrm{C}$. Hasil ini berbeda jika dibandingkan penelitian yang dilakukan oleh Taspika (2014). Pada penelitian tersebut ukuran pori semakin kecil dengan meningkatnya suhu aktivasi. Dapat disimpulkan ukuran pori mulai membesar jika suhu aktivasi diatas $700{ }^{\circ} \mathrm{C}$.

Mengecilnya ukuran pori sampai suhu aktivasi $700{ }^{\circ} \mathrm{C}$ disebabkan oleh naiknya energi panas. Energi panas yang semakin besar mengakibatkan partikel bergerak lebih cepat sehingga bertumbukan satu sama lain. Akibat dari tumbukan ini partikel terpecah menjadi lebih kecil sehingga menghasilkan pori yang lebih kecil. Kemudian ukuran pori yang semakin besar pada suhu $800{ }^{\circ} \mathrm{C}$ disebabkan oleh lebih banyaknya zat aktivator yg menguap. Peryataan ini didasarkan pada Gambar 3 (a) dan (b). Pada gambar tersebut terlihat masih adanya aktivator berwarna putih sedangkan pada Gambar 3 (c) tidak terdapat hal seperti itu. Sehingga dapat diasumsikan semakin besar suhu aktivasi yang diberikan maka aktivator yang menguap juga semakin besar.

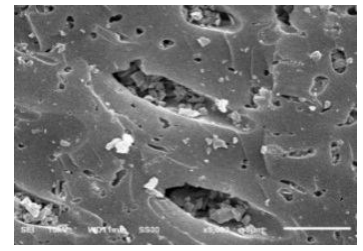

(a)

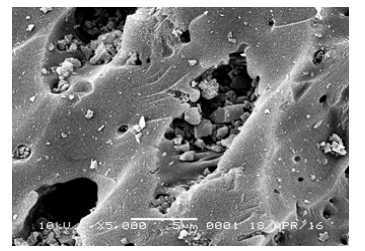

(b)

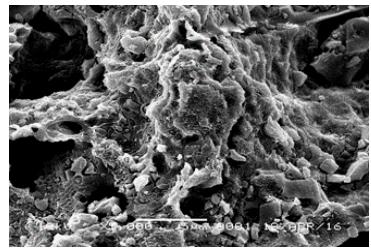

(c)

Gambar 3 Hasil foto SEM karbon aktif perbesaran 5000x dengan suhu aktivasi (a) $600{ }^{\circ} \mathrm{C}$ (b) $700{ }^{\circ} \mathrm{C}$ (c) $800{ }^{\circ} \mathrm{C}$

Untuk mengetahui jumlah dan diameter pori yang dihasilkan dilakukan perhitungan menggunakan program ImageJ. Setelah didapatkan jumlah dan diameter pori, selanjutnya diklasifikasi yang tergolong mesopori dan hasilnya disajikan dalam bentuk grafik pada Gambar 4. Pada Gambar 4 terlihat bahwa jumlah mesopori terbanyak terdapat pada karbon aktif dengan suhu aktivasi $700{ }^{\circ} \mathrm{C}$ yang berjumlah 2253 pori. Karbon aktif dengan suhu aktivasi $800{ }^{\circ} \mathrm{C}$ hanya diperoleh 924 pori dan untuk suhu aktivasi $600{ }^{\circ} \mathrm{C}$ hanya diperoleh 105 pori. Jumlah pori yang besar pada suhu aktivasi $700{ }^{\circ} \mathrm{C}$ disebabkan oleh energi panas yang diterima lebih besar. Sedangkan jumlah pori yang menurun pada suhu aktivasi $800{ }^{\circ} \mathrm{C}$ disebabkan oleh lebih banyaknya jumlah aktivator yang menguap. 
Kemudian luas permukaan pori dari karbon aktif pada juga dihitung menggunakan program ImageJ yang kemudian ditampilkan pada Tabel 1. Dari Tabel 1 terlihat bahwa luas permukaan pori yang paling besar terdapat pada karbon aktif dengan suhu aktivasi $700{ }^{\circ} \mathrm{C}$. Hal ini disebabkan oleh banyaknya jumlah pori yang terbentuk. Jumlah pori yang terbentuk akan meningkatkan luas permukaan pori dari karbon aktif. Semakin banyak jumlah pori yang dihasilkan maka luas permukaan pori juga akan semakin besar.

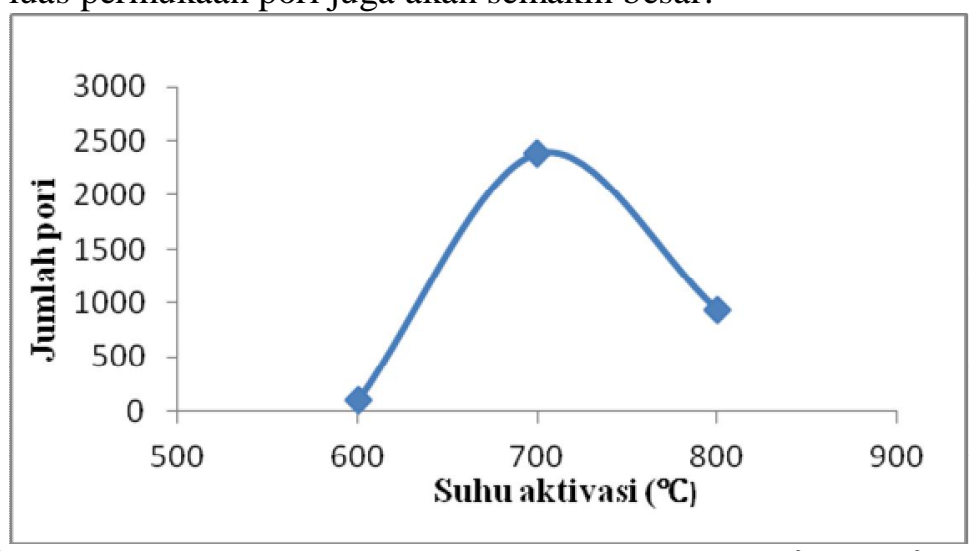

Gambar 4 Grafik jumlah mesopori dengan suhu aktivasi $600{ }^{\circ} \mathrm{C}, 700^{\circ} \mathrm{C}$ dan $800{ }^{\circ} \mathrm{C}$.

Tabel 1 Tabel luas permukaan pori karbon aktif

\begin{tabular}{ccc}
\hline No & Suhu Aktivasi $\left({ }^{\mathbf{0}} \mathbf{C}\right)$ & $\begin{array}{c}\text { Luas permukaan pori } \\
\left(\mathbf{n m}^{\mathbf{2}}\right)\end{array}$ \\
\hline 1 & 600 & 444426,57 \\
2 & 700 & 12910253,53 \\
3 & 800 & 3466400,00 \\
\hline
\end{tabular}

\subsection{Konduktivitas Listrik dan Kapasitansi Elektroda}

LCR meter digunakan untuk melihat nilai konduktivitas listrik dan kapasitansi dari elektroda yang dihasilkan. Elektroda dibuat menggunakan karbon aktif dengan variasi aktivasi $600{ }^{\circ} \mathrm{C}, 700{ }^{\circ} \mathrm{C}$, dan $800{ }^{\circ} \mathrm{C}$. Hasilnya dapat dilihat pada Gambar 5 dan 6 .

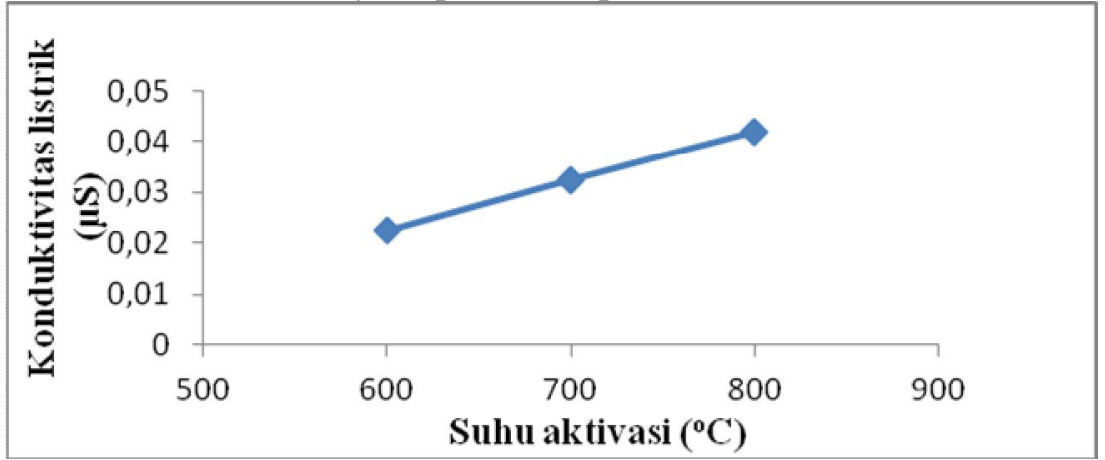

Gambar 5 Grafik perbandingan konduktivitas listrik elektroda karbon aktif dengan suhu aktivasi $600{ }^{\circ} \mathrm{C}, 700{ }^{\circ} \mathrm{C}$ dan $800{ }^{\circ} \mathrm{C}$

Pada Gambar 6 terlihat dengan meningkatnya suhu aktivasi maka nilai konduktivitas listrik elektroda juga meningkat. Peningkatan nilai konduktivitas listrik disebabkan oleh mengecilnya ukuran partikel akibat kenaikan suhu. Partikel yang semakin kecil akan menyebabkan mobilitas elektron semakin besar sehingga mengakibatkan daya hantar listrik menjadi besar. Besar nilai konduktivitas listrik dipengaruhi oleh mobilitas elektron. 


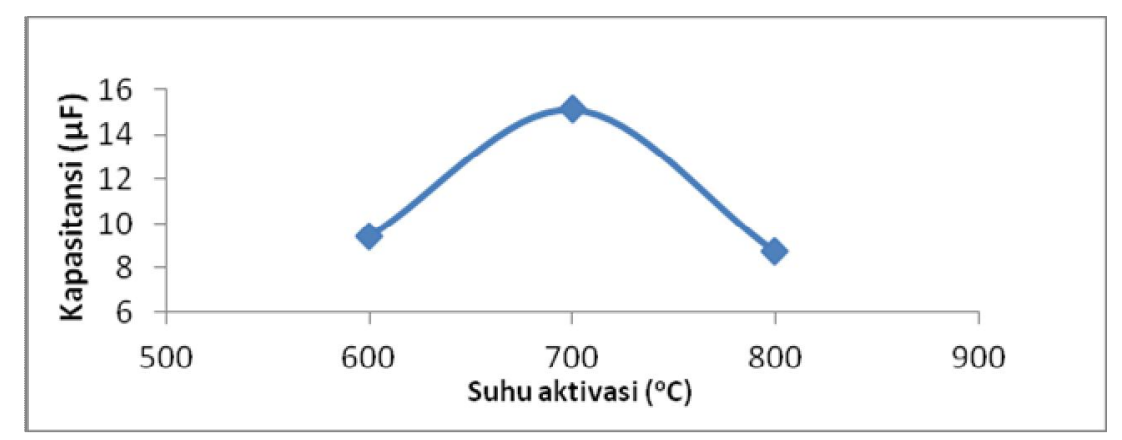

Gambar 6 Grafik perbandingan kapasitansi listrik elektroda karbon aktif dengan suhu aktivasi $600{ }^{\circ} \mathrm{C}, 700{ }^{\circ} \mathrm{C}$ dan $800{ }^{\circ} \mathrm{C}$.

Gambar 6 menampilkan nilai kapasitansi dari masing-masing elektroda dengan suhu aktivasi yang berbeda. Pada Gambar 6 terlihat kapasitansi meningkat dari suhu aktivasi $600{ }^{\circ} \mathrm{C}$ ke $700{ }^{\circ} \mathrm{C}$ dan mengalami penurunan pada suhu $800{ }^{\circ} \mathrm{C}$. Hasil yang didapatkan ini tidak sebanding dengan nilai konduktivitas listrik yang berbanding lurus dengan suhu aktivasinya. Kenaikan nilai kapasitansi dari $600{ }^{\circ} \mathrm{C}$ ke $700{ }^{\circ} \mathrm{C}$ disebabkan oleh meningkatnya luas permukaan pori yang dihasilkan (Tabel 1). Dengan luas permukaan yang lebih besar maka nilai kapasitansi menjadi lebih besar. Sedangkan penurunan nilai kapasitansi pada suhu $800{ }^{\circ} \mathrm{C}$ diakibatkan oleh menurunnya luas permukaan, sehingga kapasitansi yang dihasilkan juga semakin kecil (Tabel 1).

\section{KESIMPULAN}

Dari penelitian yang telah dilakukan dan analisis mengenai diameter pori, jumlah pori, luas permukaan pori maka dapat disimpulkan bahwa karbon aktif dengan suhu aktivasi $700{ }^{\circ} \mathrm{C}$ merupakan material yang paling baik digunakan sebagai elektroda. Sedangkan berdasarkan data konduktivitas listrik dan kapasitansi, elektroda yang terbaik diperoleh dengan aktivasi $700{ }^{\circ} \mathrm{C}$. Jadi, suhu aktivasi yang paling baik untuk pembuatan karbon aktif sebagai elekroda CDI adalah $700{ }^{\circ} \mathrm{C}$.

\section{DAFTAR PUSTAKA}

Adhytiawan, A. A., dan Susanti, D., 2013, Pengaruh Variasi Waktu Hidrotermal terhadap Sifat Kapasitif Superkapasitor Material Graphene, Jurnal Tenik Pomits, Vol.2, No.1, Jurusan Teknik Material dan Metalurgi Institut Teknologi Sepuluh November, hal 45-50.

Ariyanto, T., Prasetyo, I., dan Rochmadi, 2012, Pengaruh Struktur Pori Terhadap Kapasitansi Elektroda Superkapasitor Yang di Buat dari Karbon Nanopori, Reaktor, Vol.14, No.1, Jurusan Teknik Kimia Universitas Gajah Mada, hal 25-31

Darmawan, S., Pari, G., dan Sofyan, K., 2009, Optimasi Suhu dan Lama Aktivasi dengan Asam Phosfat dalam Produksi Arang Aktif Tempurung Kemiri, Jurnal Ilmu dan Teknologi Hasil Hutan, Vol.2, No.2, Balai Penelitian Kehutanan Mataram, hal 51-56.

Endarko, dan Fatimah, I., 2013, Fabrikasi dan Karakterisasi Elektroda untuk Sistem Capacitive Deionization (CDI) pada Proses Desalinasi Larutan $\mathrm{NaCl}$ dengan Metode FreezingThawing, Jurnal Teori dan Aplikasi Fisika, Vol.1, No.2, Jurusan Fisika Institut Teknologi Sepuluh November, hal 137-144.

Gonzalez, M. C. F., Serrano, G. V., Cervantest, M. R., Franco, A., dan Garcias, A. M., 2003, Carbonization and demineralization of coals: A study by means of FT-IR spectroscopy, Matter, Vol.26, No.7, Indian Academy of Science.

Lempang, M., Syafii, W., dan Pari, G., 2009, Struktur dan Komponen Arang Serta Arang Aktif Tempurung Kemiri, Jurnal Hasil Penelitian Hutan, Vol.29, No.3, Pusat Penelitian dan Pengambangan Keteknikan kahutanan dan Pengolahan Hasil Hutan, hal 278-294.

Nienhuis, P. H., 2006, Water and Values: Ecological Research as The Basis for Water Management and Nature Management, Living Rivers: Trends and Challenger in Science and Management, Vol.265, Springer, hal 261-275. 
Misbah, M. N., dan Nova, S. M. K., 2010, Analisi Pengaruh Salinitas dan Suhu Air Laut Terhadap Laju Korosi Baja A36 pada Pengelasan SMAW, Jurnal Teknik ITS, Vol.1, Jurusan Teknik Perkapalan Institut Teknologi Sepuluh November, hal 75-77.

Raman, V. K., Varigala, S. K., dan Pariyarath, P. N., 2014, Develoment and Evaluation of an Electrode for the Capacitive Deionization Unit, Journal of Enviromental Science, Vol.8, Centre of Biotechnology Water and Wastewater Technology, hal 40-44.

Ramdja. A. F., Kurniawan, A., dan Ahmad, S., 2008, Pembuatan Karbon Aktif dari Coalite Batubara dan Aplikasinya Dalam Pengolahan Limbah Cair Industri Kain Jumputan, Jurnal Teknik kimia, Vol.15, No.4, Jurusan Teknik Kimia Universitas Sriwijaya, hal 17.

Taberna, P. L., Chevallier, G., Plee, D., Aubert, T., dan Simon, P., 2004, Activated CarbonCarbon Nanotube Composite Porous Film for Supercapacitor Applications, Materials Research Bulletin, Vol.41, Elsevier, hal 478-484.

Taspika, M., 2014, Pembuatan Elektroda Kapasitor Karbon Berpori dari Tempurung Kemiri (Aleurites moluccana) dan Perancangan Prototipe Sistem Capacitive Deionization (CDI) untuk Desalinasi Air Payau, Skripsi, FMIPA, Universitas Andalas, Padang. 